Volume 2 Nomor 2 Tahun 2020

e-ISSN: 2655-948X

http://u.lipi.go.id/1548306171

\title{
PERENCANAAN KURIKULUM PEMBELAJARAN DI TAMAN BACAAN MASYARAKAT (TBM) ASY- SYIFA DALAM MENUNJANG TUJUAN PENDIDIKAN AGAMA ISLAM DI DESA CUMEDAK KECAMATAN SUMBERJAMBE KABUPATEN JEMBER
}

\author{
Nurul Anam, Murtasiyatul Jannah \\ Institut Agama Islam Al-Qodiri Jember, Jawa Timur \\ e-mail: nurul.anam86@gmail.com,mustasiyatul23@gmail.com
}

Diterima: 06 September 2020 | Direvisi: 27 November 2020 | Disetujui: 27 November 2020

(C) 2018 Program Studi Pendidikan Agama Islam Fakultas Agama Islam Universitas Islam Malang

\begin{abstract}
Curriculum planning is one of the components that have an important role in the education curriculum system, because the main component of the curriculum is not only about the implementation and evaluation of the curriculum, but the curriculum component also discusses about curriculum planning. Curriculum planning must be considered by educational institutions in order to run optimally. In TBM Asy-syifa Village Cumedak Kec. Sumberjambe Kab. Jember, curriculum planning is carried out to the maximum. From the research background, this research will describe about Curriculum Planning in TBM Asy-syifa Village Cumedak Kec. Sumberjambe Kab. Jember. The approach in this research is qualitative approach, with data analysis using Triangulation. To collect data using methods such as: observation method, interview method and documentation method, so that the data collected becomes valid, it is used the validity of situation triangulation data and source triangulation. The results showed that the planning of the learning curriculum in TBM Asy-syifa Village Cumedak Kec. Sumberjambe Kab. Jember starting from the basic curriculum planning, seeking information from the surrounding community, government guidelines on education outside the school.
\end{abstract}

Keyword: curriculum planning, community reading park

\begin{abstract}
Abstrak
Perencanaan kurikulum merupakan salah satu komponen yang memiliki peran penting dalam sisitem kurikulum pendidikan, sebab komponen utama kurikulum bukan hanya tentang pelaksanaan dan evaluasi kurikulum, akan tetapi komponen kurikulum juga membahas tentang perencanaan kurikulum. Perencanaan kurikulum harus diperhatikan oleh lembaga pendidikan agar pelaksanaannya berjalan dengan maksimal. Di TBM Asysyifa Desa Cumedak Kec. Sumberjambe Kab. Jember, perencanaan kurikulum
\end{abstract}

This work is licensed under Creative Commons Attribution Non Commercial 4.0 International License Available online on: http://riset.unisma.ac.id/index.php/fai/index 
dilaksanakan secara maksimal. Dari latar penelitian maka penelitian ini akan mendiskripsikan tentang Perencanaan Kurikulum di TBM Asy-syifa Desa Cumedak Kec. Sumberjambe Kab. Jember. Pendekatan dalam penelitian ini adalah pendekatan kualitatif, dengan analisa data menggunakan Triangulasi. Untuk mengumpulkan data menggunakan metode yaitu: metode observasi, metode interview dan metode dokumentasi, agar data yang dikumpulkan menjadi valid maka digunakan keabsahan data Triangulasi situasi dan Triangulasi sumber. Hasil penelitian menunjukkan bahwa perencanaan kurikulum pembelajaran di TBM Asy-syifa Desa Cumedak Kec. Sumberjambe Kab. Jember di mulai dari perencanaan kurikulum dasar, mencari informasi dari masyarakat sekitar, pedoman pemerintah tentang pendidikan luar sekolah.

Kata Kunci: perencanaan kurikulum, taman bacaan masyarakat

\section{Pendahuluan}

Kurikulum merupakan salah satu komponen yang memiliki peran penting dalam sisitem pendidikan, sebab dalam kurikulum bukan hanya dirumuskan tentang tujuan yang harus dicapai sehingga memperjelas arah pendidikan, akan tetapi juga memberikan pemahaman tentang pengalaman belajar yang harus dimiliki setiap siswa. Di dalam kurikulum sebagaimana dalam UU No 20 Tahun 2003, terdapat berbagai unsur kurikulkum yaitu tujuan, isi, Bahan/Alat/Media Pembelajaran, cara/strategi dan evaluasi pembelajaran (Nurul Anam dan Moh. Rofid Fikroni, 2020: 77-78). Menurut Nana Saodih Sukmadinata (1999: 4) Kurikulum merupakan suatu rencana pendidikan, memberikan pedoman dan pegangan tentang jenis, lingkup dan urutan isi, serta proses pendidikan.

Di dalam kurikulum, terdapat perencanaan kurikulum. Perencanaan kurikulum merupakan upaya untuk merancang berbagai komponen kurikulum baik tujuan, isi, Bahan/Alat/Media Pembelajaran, cara/strategi maupun evaluasi pembelajaran untuk digunakan dalam proses pembelajaran. Perancangan kurikulum ini sangat signifikan digunakan dalam proses pendidikan dan pembelajaran.

Ternyata manfaat manajemen kurikulum tersebut juga dirasakam di Taman Bacaan Masyarakat (TBM) Asy- Syifa Cumedak Kecamatan Sumberjambe Kabupaten Jember. TBM Asy- Syifa Merupakan Subuah Taman Bacaan Masyarakat yang didalamnya bukan hanya terdapat buku- buku yang menarik untuk dibaca tetapi juga banyak Kegiatan yang dilakukan setiap minggunya. TBM ini sudah menerapkan manajemen kurikulum (Observasi, 02 Agustus 2017).

Manajemen kurikulum yang diterapkan disana meliputi: perencanaan, pelaksanaan, dan evaluasi kurikulum. Perencanaan kurikulum disana sudah 
direncanakan dengan matang sehingga pelaksanaan kurikulumpun berjalan dengan baik dan lancar. Pelaksanaan kurikulum yang ada disana lebih menekankan pada pengembangan potensi dan kegiatan yang dilakukan setiap minggunya, yaitu mengadakan perpustakaan keliling disetiap sekolah dan desa sekitar desa cumedak. Selain pelaksanaan kurikulum TBM Asy-Syifa juga menerapkan evaluasi kurikulum. Evaluasi kurikulum dilaksanakan setiap selesai mengadakan sebuah agenda kegiatan. Dengan adanya evaluasi ini para anggota TBM Asy- Syifa bisa mengadakan kegiatan- kegiatan baru yang lebih baik dan menarik dalam membiasakan masyarakat agar lebih gemar membaca (Observasi, 02 Agustus 2017).

Kebermanfaatan dari proses perencanaan kurikulum TBM Asy-Syifa dapat di rasakan masyarakat luas khususnya masyarakat sekitar. Hal ini selaras dengan nilai dari tujuan Pendidikan Agama Islam sesuai dengan PP nomor 55 tahun 2007 yang intinya adalah Pendidikan Agama bertujuan untuk mengembangkan kemampuan peserta didik dalam memahami, menghayati, dan mengamalkan nilai agama dalam mengkorelasikan penguasannya terhadap ilmu pengetahuan, teknologi, dan seni. Melalui edukasi membaca selangkah berkontribusi dalam membasmi buta wawasan dan pengetahuan. Membaca pula ilmu yang didapatkan Rasul pertama kali menerima wahyu Allah sebagaimana dalam surat al Alaq 1-5.

Informasi atau berita merupakan hal yang sangat penting dalam kehidupan di zaman sekarang ini, hampir setiap hari kita mendapatkan berita- berita dari berbagai media massa, mulai dari surat kabar, radio, televise, sampai internet. Dari snilah kita gampang dalam mendapatka informasi. Akan tetapi kenyataannya banyak masyarakat yang ada disebagian wilayah sumberjambe tidak bias menjangkau informasi atau berita dari luar, dikarenakan tidak adanya fasilitas yang memadai. Oleh sebab itulah dengan adanya kegiatan yang dilakukan oleh TBM asysyifa di harapkan agar masyarakat lebih gampang dalam menjangkau informasi dari luar (Observasi, 04 Agustus 2017).

Oleh sebab itulah, perencanaan kurikulum pembelajaran yang diterapkan di TBM Asy- Syifa sangat menarik untuk dijadikan penelian, disamping memikili kurikulum yang berbeda dengan lembaga pendidikan lainnya, penerapan kurikulumnya berhasil dan juga pembelajaran yang diterapkan berjalan dengan baik dan efektif.

\section{Metode}

Dalam suatu penelitian dituntut adanya teknik tertentu untuk mendapatkan data-data yang dibutuhkan. Sehingga dapat berhasil dengan baik untuk memahami dan memecahkan masalah penelitian, maka dipergunakan langkah-langkah yang 
antara lain: pendekatan penelitian, penentuan objek penelitian teknik pengumpulan data, analisa data, serta validitas data.

Sebuah penelitian memerlukan pendekatan penelitian yang dipilih, yaitu penelitian jenis kualitatif. Penelitian jenis ini misalnya mengambil jenis studi kasus, etnografi, penelitian tindakan kelas, dan atau jenis lainnya (TIM STAIQOD, 2012: 70).

Lokasi penelitian yang peneliti pilih adalah di TBM Asy-Syifa Cumedak kecamatan Sumberjambe Kabupaten Jember. Subyek penelitian adalah informan dan hal-hal lain yang menjadi sumber penelitian. Dalam memperoleh informan peneliti harus hati-hati, tidak langsung menunjuk satu orang yang dianggap memahami permasalahan tetapi mata dan telinga dibuka lebar-lebar sehingga menemukan orang yang memang paling tahu tentang variabel yang diteliti (Arikunto, 2010: 23) Adapun informan dalam penelitian ini adalah: Kepala Sekolah, Guru, dan Siswa.

Pengumpulan data adalah cara-cara yang digunakan dalam penelitian untuk mengumpulkan data, menghimpun data, dan memperoleh data yang valid. Sebelum pengumpulan data dahulu mengadakan uji cobe/latihan, agar diperoleh data yang sesuai dengan harapan. Peneliti melakukan teknik pengumpulan data dengan metode antara lain: metode observasi, metode interview dan metode dokumentasi.

Di dalam penelitian ini mengggunakan teknik analisa data triangulasi, dimana penemuan yang di peroleh melalui satu pendekatan dapat dipakai untuk melakukan pengecekan terhadap hasil yang diperoleh dari pendekatan yang lain. Tringulasi sumber/data yaitu teknik pengumpulan data yang bersifat menggabungkan dari berbagai teknik pengumpulan data atau sumber data yang telah ada. Sehingga dalam penelitian mendapat hasil penelitian yang maksimal di TBM Asy-Syifa Cumedak kecamatan Sumberjambe Kabupaten Jember. Untuk memperoleh hasil analisis yang tepat digunakan dengan cara: Reduksi Data, Penyajian Data dan Penarikan Kesimpulan/Verifikasi. Sebagai penjelasan lebih rinci sebagai berikut:

Di dalam penelitian ini akan diadakan uji keabsahan data dengan maksud untuk memperoleh data yang valid, yaitru data dari informasi yang memiliki kesamaan dari waktu ke waktu , antara informan yang satu dengan informan yang lain (Suprayogo, 200:140). Oleh karena itu teknik yang tepat untuk menguji keabsahan data dengan teknik trianggulasi situasi dan trianggulasi sumber. Trianggulasi situasi digunakan untuk mengkonfirmasikan informasi yang diperoleh dari informan satu dengan yang lainnya pada situasi yang berbeda. Sedangkan trianggulasi sumber digunakan untuk meng-crosscheck kebenaran informasi dari informan yang satu kepada informan yang lain yang diperoleh setelah rampung 
mengadakan penelitian lapangan, yaitu di TBM Asy-Syifa Cumedak kecamatan Sumberjambe Kabupaten Jember. Dengan cara demikian diharapkan kabsahan data dapat dipertanggungjawabkan.

Dalam melaksanakan penelitian, peneliti akan melalui tahapan-tahapan sebagaimana dijelaskan Moleong (2007:127-128), yang ditetapkan sebagai berikut:

1. Tahap Pra-lapangan. Dalam tahap ini peneliti menyiapkan berbagai keperluan sebelum terjun ke lapangan, termasuk kesiapan etika dan mental dan administrasi sebelum penelitian (termasuk perijinan) baik dari STAI AL-Qodiri Jember maupun dari TBM Asy-Syifa Cumedak kecamatan Sumberjambe Kabupaten Jember.

2. Tahap Pekerjaan Lapangan. Dalam tahap ini peneliti: (1).memahami latar penelitian ; (2).memasuki lapangan; dan (3).mengumpulkan data terkait dengan TBM Asy-Syifa Cumedak kecamatan Sumberjambe Kabupaten Jember. Tahap Analisa data hasil penelitian. Dalam tahap ini peneliti menganalisis hasil temuan dan membahasanya sampai memperoleh kesimpulan akhir. Setelah semua proses penelitian dan penulisan rampung, peneliti menyusun menjadi laporan penelitian berbentuk skripsi .

\section{Hasil dan Pembahasan}

\section{Relevansi Taman Baca al Qur'an dan Pendidikan Islam}

Tujuan Pendidikan Islam sebagaimana dikemukakan para tokoh Islam klasik adalah mempersiapkan peserta didik untuk memiliki ilmu kemasyarakatan, sosial, dan kesenian (Wiyono DF, 2017: 167). Oleh karena itu sangat sesuai dengan kemunculan Tamn Baca Msayarakat yang mengajarkan ketiga ilmu tersebut sesuai tujuan Pendidikan Isam. Berbagai macam definisi Taman Baca Masyarakat (TBM) dikemukakan oleh para ahli, dan belum ditemukan definisi tunggal hasil kesepakatan bersama tentang TBM. Beberapa sumber mendifinisikan Taman bacaan masyarakat merupakan lembaga yang membudayakan kesenangan masyarakat membaca dengan memberikan layanan dan penyediaan bahan bacaan seperti buku, tabloid, majalah, komik, koran dan multimedia lainnya dengan fasilitas ruang untuk diskusi menulis, dan bedah buku yang didukung oleh motivator yang diperankan oleh pengelola (Rahmwati dkk, 2012: 30).

TBM adalah "Suatu lembaga yang melayani kebutuhan masyarakat akan informasi mengenai ilmu pengetahuan dalam bentuk bahan bacaan dan bahan pustaka lainnya" (Kalida, 2012: 2). TBM dapat dinyatakan sebagai "Perpustakaan yang sangat dekat dengan masyarakat karena sasaran utamanya adalah warga 
masyarakat, terutama di daerah yang sulit dijangkau oleh perpustakaan umum (perpustakaan desa maupun perpustakaan daerah)" (Rahmwati dkk, 2012: 29).

Keberadaan Taman Baca dapat mengsukseskan tujuan dalam beragama Islam adalah menjadi insan kamil artinya manusia sempurna dengan keutuhan imannya yang didasari dengan kemampuan membaca al-Qur'an. Sehingga penting sekali membangun spirit literasi Islam dalam mencapai visi agama Islam. Literasi sebagai kunci dan alat menjadikan manusia sebagai makhluk mulia karena ilmu pengetahuan yang dimilikinya.

Istilah Literasi Islam memiliki dua kata yang berbeda. Literasi secara umum diartikan "Sebagai sebuah kemampuan membaca dan menulis.57 Islam adalah "Agama yang berisi ajaran tentang tata hidup yang diturunkan Allah kepada umat manusia melalui para rasulnya, sejak dari Nabi Adam sampai kepada Nabi Muhammad".58 Jadi, literasi Islam adalah kemampuan membaca dan menulis seseorang dalam memahami ajaran-ajaran agama Islam.

Minat baca merupakan dorongan untuk memahami kata demi kata dan isi yang terkandung dalam teks bacaan tersebut, sehingga pembaca dapat memahami halhal yang dituangkan dalam bacaan itu. Minat baca adalah kemauan atau keinginan seseorang untuk mengenali huruf untuk mengungkap makna dalam tulisan tersebut. Minat membaca merupakan kemampuan seseorang dalam berkomunikasi dengan diri sendiri untuk mengungkap makna yang terkandung dalam tulisan sehingga memberikan pengalaman emosi akibat dari bentuk perhatian yang mendalam terhadap makna bacaan (Dalman, 2013: 141).

Oleh karena itu, penting sekali keberadaan pengelolaan Taman Baca Masyarakat melalui ilmu manajemen. Keberadaanya menunjang pengaturan kegiatan agar dapat berjalan baik sesuai dengan perencanaan yang telah didesain dengan matang. Dalam ilmu Manajaemen terdapat 4 aspek dalam pengelolaan diantaranya: perencanaan, pengorganisasian, pelaksanaan, dan evaluasi. Perencanaan disini akan dibahas dan direlevansikan dengan kurikulum TBM. Didalam melaksanakan empat aspek tersebut dibutuhkan pemimpin yang mempunyai visi-misi yang jelas dan bisa mengintegrasikan dari semua aspek (safi'i, 2020: 224).

\section{Perencanaan kurikulum di TBM Asy-syifa Desa Cumedak Kecamatan Sumberjambe Kabupaten Jember}

Terdapat dua kondisi yang perlu di analisis dalam perencanaan kurikulum yaitu sebagai berikut: 
a. Kondisi sosokultural Kemampuan professional manajerial menuntut kemampuan untuk dapat mengolah atau memanfaatkan berbagai sumber yang ada di masyarakat untuk di jadikan narasumber

b. Ketersediaan fasilitas dalam merencakan kurikulum perlu adanya kesesuaian dengan adanya ketersediaan fasilitas yang dimiliki setiap lembaga pendidikan.

Berdasrkan hasil Observasi Adanya manajemen kurikulum memang sangat berpengaruh dalam suatu lembaga pendidikan. Kurikulum yang diterapkandi TBM Asy-syifa memang berbeda dengan kurikulum yang ada di lembaga pendidikan formal, mereka memiliki kurikulum tersendiri, kurikulumnya lebih menekankan pada pendekatan terhadap masyarakat di sekitar Desa Cumedak, agar para masyarakat bisa gemar membaca dan mengurangi adanya masyarakat yang masih buta huruf (Observasi, Jember 05 Agustus 2017).

Berdasarkan hasil Observasi peneliti dapat ditemukan bahwa perencanaan kurikulum di TBM Asy- Syifa sudah direncanakandengan baik dan matang, sehingga kurikulum yang diterapkan sudah terbilang cukup berhasil. Dalam proses perencanaan TBM Asy- Syifa mempersiapkan beberapa hal sebagai dasar dalam perumusan kurikulum, yang pertama mencari informasi dari masyarakat dan anakanak disekitar tentang apa yang mereka butuhkan agar mereka bisa gemar membaca, kedua berpedoman pada pedoman pemerintah tentang pendidikan diluar sekolah (Observasi, Jember 05 Agustus 2017).

Sebagaimana hasil wawancara peneliti dengan kepala TBM Asy-syifa yaitu sebagai berikut:

Perencanaan kurikulum di TBM Asy-syifa dimulai dari kurikulum dasar, informasi dari masyarakat sekitar yaitu apa yang diinginkan masyarakat dan bagaimana membuat masyarakat sekitar gemar membaca dan mengurangi masyarakat yang masih buta huruf, Pedoman pemerintah tentang pendidikan non formal. Dengan perencanaan kurikulum tersebut diharapkan kurikulum yang kita terapkan akan terlaksana dengan baik dan efektif. (Malwina Turrahmah S.Pd.I, wawancara, Jember 16 juli 2017)

Berdasarkan dari hasil wawancara di atas perencanaan kurikulum harus direncanakandengan matang agar pelaksanaan kurikulum dapat berjalan dengan baik dan efektif.

Penulis juga mewawancarai Nurfadilah selaku Pengurus TBM yaitu sebagaimana yang ada di bawah ini:

Perencanaan kurikulum di TBM Asy-syifa sudah lumayan baik dalam merencanakan kurikulum sebelumnya kita mengadakan rapat anggota, ketua TBM, serta ketua PKBM yang ikut hadir di dalamnya agar mendapatkan hasil 
yang maksimal dan kurikulum yang kita terapkan bisa berjalan dengan baik dan lancar. (Nurfadilah S.Pd.I, wawancara, Jember 21 Juli 2017)

Mengadakan musyawaroh dengan anggota, ketua TBM, serta ketua yayasan dalam merencakan kurikulum adalah salah satu kegiatan yang harus dilaksakan dalam merencanakan kurikulum.

Menurut Syamsiah selaku pengurus TBM Asy- Syifa mengatakan sebagai berikut:

Perencanaan kurikulum di TBM asy- syifa dilakukan dengam mengadakan rapat kepala pkbm, ketua dan pengurus TBM, kita bersama-sama merancang kurikulum yang nantinya bisa digunakan di TBM asy- syifa dan pelaksanaan kurikulumpun bisa berjalan dengan baik dan lancer (Syamsiah, wawancara, Jember 21 Juli 2017).

Mengadakan rapat ketua PKBM, ketua dan pengurus TBM merupakan kegiatan yang sangat penting dalam merencanakan kurikulum, kegiatan ini dilakukan agar pelaksanaan kurikulum terencana dengan baik dan maksimal sehingga nantinya bisa berjalan dengan lancar.

Peneliti juga mewawancarai satrul umam selaku pengurus TBM asy- syifa yaitu sebagai berikut:

Perencanaan kurikulum di TBM asy- syifa dilakukan dengan melihat antusias masyarakat agar gemar membaca, dengan hal ini kita bisa merancang kegiatan apa yang akan dilakukan agar menumbuhkan minat masyarakat untuk lebih gemar membaca (Satrul umam, wawancara, Jember 21 Juli 2017).

Dari penjelasan tersebut dapat disimpulkan bahwa mengetahui keinginan masyarakat agar gemar membaca merupakan salah satu hal penting dalam perencanaan kurikulum, dengan mengetahui hal ini para pengurus dan ketua TBM bisa merencanakan kegiatan yang nantinya akan menumbuhkan minat masyarakat untuk lebih gemar membaca.

Menurut Nurul selaku anggota TBM asy- syifa mengatakan sebagaimana berikut ini:

Perencanan kurikulum TBM asy- syifa dilakukan oleh ketua dan pengurus TBM, dalam merencanakan kurikulum mereka mengadakan rapat terlebih dahulu sehingga pelaksanaan kurikulum disini berjalan dengan baik dan lancar, masyarakat banyak yang antusias dengan adanya kegiatan tersebut (Nurul, wawancara, Jember 26 Juli 2017)..

Berdasarkan penjelasan tersebut perencanan kurikulum di TBM asy- syifa dilakukan oleh ketua dan pengurus TBM. Dalam melaksanakan kurikulum diadakan 
rapat sehingga pelaksanan kurikulum yang diterapkan dapat berjalan dengan baik dan lancer.

Berdasarkan hasil Dokumentasi Perencanan Kurikulum di TBM asy- syifa sudah dilakukan, perencanan tersebut dilakukandengan mengadakan rapat ketua PKBM, ketua dan pengurus TBM, perencanan kurikulum di TBM asy- syifa dimulai dari pertama merencanakan kurikulum dasar yaitu menetapkan tujuan, visi, misi serta tata tertib TBM, kedua mengetahui keinginan masyarakat misalnya: apa yang dibutuhkan masyarakar agar mereka gemar membaca, ketiga pedoman pemerintah tentang pendidikan diluar sekolah (Dokumentasi, Jember11 Agustus 2017).

Dalam perencanaan kurikulum TBM terdapat aspek peningkatan Sumber Daya Manusia terdapat pada tujuan dan diterjemahkan dalam bentuk program Jangka Pendek sebagai output lembaga. Keberadannya memberikan kontribusi dalam peningkatan mutu SDM yang disesuaikan dengan perkembangan dan kebutuhan masyarakat (Sa'dullah dan Hidayatullah MF, 2020: 266). Berikut perencanaan kurikulum di TBM asy- syifa sebagaimana tabel di bawah ini:

Tabel 1

Visi, Misi dan Tujuan TBM Asy- Syifa Cumedak Sumberjambe

\begin{tabular}{|l|}
\hline \multicolumn{2}{|c|}{ Visi } \\
\hline $\begin{array}{l}\text { 1. Menjadikan masyarakat gemar membaca } \\
\text { 2. Menjadikan masyarakat yang sejahtera }\end{array}$ \\
\hline $\begin{array}{l}\text { Misi } \\
\text { masyarakat untuk membaca, menulis, berfikir dan } \\
\text { mengembangkan diri melalui TBM Asy Syifa }\end{array}$ \\
\hline $\begin{array}{l}\text { 1. Tujuan } \\
\text { 2. Menjadikan budaya baca sebagai gaya hidup masyarakat }\end{array}$ \\
\hline
\end{tabular}

Sumber data : Dokumentasi TBM Asy- syifa Desa Cumedak Kec. Sumberjambe Kabupaten Jember

Tabel 2

\section{Program TBM Asy- Syifa Cumedak Sumberjambe}




\begin{tabular}{|c|c|}
\hline SUB-KOMPONEN /INDIKATOR & URAIAN \\
\hline \multicolumn{2}{|c|}{ PROG. JANGKA PENDEK } \\
\hline $1.2007 \mathrm{~s} / \mathrm{d} 2012$ & $\begin{array}{l}\text { Peningktan SDM Pengelola, Buku Pustaka, } \\
\text { Akses Jejaring, Sosialisasi, minat baca, } \\
\text { Gedung sendiri }\end{array}$ \\
\hline $2.2012 \mathrm{~s} / \mathrm{d} 2013$ & $\begin{array}{l}\text { Penguatan Akses, Buku Pustaka, Media } \\
\text { Audio Visual, Internet, Buka WebSide, } \\
\text { Penerapan Kiat Silaturrahim TBM, } \\
\text { Gedung Yang lebih presentatif. }\end{array}$ \\
\hline \multicolumn{2}{|c|}{ PROG.JANGAKA MENENGAH } \\
\hline 3. $2013 \mathrm{~s} / \mathrm{d} 2014$ & $\begin{array}{l}\text { Penguatan Akses, Buku Pustaka, Media } \\
\text { Audio Visul, Internet, Buka WebSide, } \\
\text { Pelayanan buku elektronik, Kerjasama } \\
\text { dengan TBM, perpustakaan elektronik } \\
\text { membentuk kampung,desa dan daerah } \\
\text { perputakaan elektronik. }\end{array}$ \\
\hline 4.2014 s/d 2017 & $\begin{array}{l}\text { Penguatan Akses, Buku Pustaka, Media } \\
\text { Audio Visul, Internet, Buka WebSide, } \\
\text { Pelayanan buku elektronik,Kerjasama } \\
\text { dengan TBM, perpustakaan elektronik di } \\
\text { Indonesia }\end{array}$ \\
\hline \multicolumn{2}{|c|}{ PROGRAM JANGKA PANJANG } \\
\hline 5. 2017 s/d 2019 & $\begin{array}{l}\text { Penguatan Akses, Buku Pustaka, Media } \\
\text { Audio Visual, Internet, Buka WebSide, } \\
\text { Pelayanan buku elektronik, Kerjasama } \\
\text { dengan perpustakaan elektronik dalam } \\
\text { dan luar negeri }\end{array}$ \\
\hline & \\
\hline
\end{tabular}


6. 2019 s/d 2022

Penguatan Akses,Buku Pustaka, Media Audio Visual, Internet, Buka WebSide, Pelayanan buku elektronik, Kerjasama dengan perpustakaan elektronik dalam dan luar negeri

Sumber data : Dokumentasi TBM Asy- syifa Desa Cumedak Kec. Sumberjambe Kabupaten Jember

Tabel 3

Jadwal Jaga Petugas Setiap Hari Tbm Asy- Syifa Cumedak Sumberjambe

\begin{tabular}{|c|l|c|l|c|l|}
\hline No & \multicolumn{1}{|c|}{ SENIN } & No & SELASA & No & \multicolumn{1}{|c|}{ RABU } \\
\hline 1 & $\begin{array}{l}\text { Imam } \\
\text { Muhyiddin }\end{array}$ & 1 & Malwinatur R & 1 & $\begin{array}{l}\text { Imam } \\
\text { Muhyiddin }\end{array}$ \\
\hline 2 & Eko Afit & 2 & Nur fadlilah & 2 & Eko Afit \\
\hline 3 & Khairil anwar & 3 & Aniswatul H & 3 & Khairl anwar \\
\hline No & KAMIS & No & JUMAT & No & SABTU \\
\hline 1 & Malwinatur R & 1 & $\begin{array}{l}\text { Imam } \\
\text { Muhyiddin }\end{array}$ & 1 & Malwinatur R \\
\hline 2 & Nur fadlilah & 2 & Eko Afit & 2 & Nur fadlilah \\
\hline 3 & Aniswatul H & 3 & Khairil anawar & 3 & Aniswatul H \\
\hline
\end{tabular}

Sumber data : Dokumentasi TBM Asy- syifa Desa Cumedak Kec. Sumberjambe Kabupaten Jember

Tabel 4

Jadwal Waktu Reguler Tbm Asy- Syifa Cumedak Sumberjambe

\begin{tabular}{|c|l|l|l|l|l|l|}
\hline JAM & SENIN & SELASA & RABU & KAMIS & JUMAT & SABTU \\
\hline $0700-08.00$ & Paket C & Paket C & Paket C & Paket C & Paket C & Paket C \\
\hline $08.00-09.00$ & PAUD & Santri & PAUD & Santri & PAUD & Santri \\
\hline $09.00-12.00$ & Umum & Umum & Umum & Umum & Umum & Umum \\
\hline ISTIRAHAT & Tutup & Tutup & Tutup & Tutup & Tutup & Tutup \\
\hline
\end{tabular}

Andragogi: Volume 2 Nomor 2, 2020 
Nurul Anam, Murtasiyatul Jannah

\begin{tabular}{|c|l|l|l|l|l|l|}
\hline $13.00-14.30$ & Umum & Umum & Umum & Umum & Umum & Umum \\
\hline $18.00-21.00$ & Umum & Umum & Umum & Umum & Umum & Umum \\
\hline MINGGU & Santri & Santri & Santri & Santri & Santri & Santri \\
\hline
\end{tabular}

Sumber data : Dokumentasi TBM Asy- syifa Desa Cumedak Kec. Sumberjambe Kabupaten Jember

Tabel 5

Jadwal Layanan Silaturrahim Tbm Asy- Syifa Cumedak Sumberjambe

\begin{tabular}{|c|l|l|l|}
\hline JAM & \multicolumn{1}{|c|}{ RABU } & \multicolumn{1}{c|}{ JUMAT } & \multicolumn{1}{c|}{ SABTU } \\
\hline \multicolumn{5}{|c|}{ Silat Pernik } \\
\hline $\begin{array}{c}08.00- \\
12.00\end{array}$ & $\begin{array}{l}\text { Ds.Gn.Malang } \\
\text { Ds.Cumedak }\end{array}$ & $\begin{array}{l}\text { Ds. } \\
\text { Sumberjambe }\end{array}$ & Ds.Randuagung \\
\hline \multicolumn{5}{|c|}{ Khunga } \\
\hline \multicolumn{4}{|c|}{ PETUGAS } \\
\hline $\begin{array}{c}08.00- \\
12.00\end{array}$ & Ds. Slateng & Ds.Cumedak & Ds. Gunung \\
\hline \multicolumn{5}{|c|}{ Malang } \\
\hline & Aniswatul & Aniswatul & Satrul Imam \\
\hline & Sulastri & Rina & Khairil Anwar \\
\hline
\end{tabular}

Sumber data : Dokumentasi TBM Asy- syifa Desa Cumedak Kec. Sumberjambe Kabupaten Jember

Berdasarkan hasil temuan data di TBM Asy-syifa Desa Cumedak Kec. Sumberjambe dapat diketahui bahwa perencanaan kurikulum di TBM Asy-syifa dimulai dari kurikulum dasar (misalnya merancang visi, misi dan tujuan serta kegiatan yang akan dilaksanakan), mencari informasi dari masyarakat sekitar maksudnya apa yang diinginkan masyarakat dan bagaimana strategi agar masyarakat gemar membaca, pedoman pemerintah tentang pendidikan diluar sekolah, selain itu dalam merencanakan kurikulum TBM Asy-syifa juga mengadakan musyawaroh dengan seluruh pengurus baik kepala maupun ketua yayasan hal ini dilakukan agar perencanaan kurikulum dapat tersusun dengan baik dan kurikulum yang kita terapkan dapat berjalan dengan lancar.

Temuan teori di atas relevan dengan teori yang di kemukakan oleh Rusman (2009:21) bahwa merencakan pembelajara merupakan bagian yang sangat penting dalam perencanaan kurikulum karena pembelajaran mempunyai pengaruh Andragogi: Volume 2 Nomor 2, 2020 
terhadap siswa dari pada kurikulum itu sendiri. Berdasarkan temuan diatas perencanaan kurikulum di TBM Asy-syifa sudah terencana dengan baik dan matang sehingga pembelajaran yang di terapkan berjalan dengan efektif.

Dengan demikian, perencanaan kurikulum di TBM Asy-syifa Desa Cumedak Kec. Sumberjambe berfungsi sebagai pedoman atau alat manajemen, yang berisi petunjuk tentang jenis dan sumber peserta yang diperlukan, media penyampaiannya, tindakan yang perlu dilakukan, sumber biaya, tenaga, sarana yang diperlukan, system control dan evaluasi, peran unsur-unsur ketenagaan untuk mencapai tujuan manajemen organisasi. Selain itu, pencanaan kurikulkum yang dilakukan di TBM tersebut juga berfungsi sebagai penggerak roda organisasi dan tata laksana untuk menciptakan perubahan dalam masyarakat sesuai dengan tujuan organisasi. Perencanaan kurikulum yang matang besar sumbangannya terhadap pembuatan keputusan oleh pimpinan, dan oleh karenanya perlu memuat informasi kebijakan yang relevan, disamping seni kepemimpinan dan pengetahuan yang telah dimilikinya. Perencanaan juga berfungsi sebagai motivasi untuk melaksanakan system pendidikan sehingga mencapai hasil optimal (Oemar Hamalik, 2010: 152). Maka dari itu perencaan kurikulum yang digunakan sangat berperan aktif dalam keefektifan suatu pembelajaran.

\section{Simpulan}

Perencanaan Kurikulum di TBM Asy-Syifa Desa Cumedak Kec. Sumberjambe Kab. Jember dimulai dari perencanaan kurikulum dasar, mencari informasi dari masyarakat sekitar, pedoman pemerintah tentang pendidikan luar sekolah. Perencanaan ini dilakukan supaya untuk mencapai tujuan yang ada di TBM AsySyifa tersebut. Perencanaan yang dilakukan oleh TBM Asy-Syifa tersebut berfungsi untuk mengefektifkan proses pembelajaran yang dilakukan di lemba pendidikan yang ada di TBM.

\section{Daftar Rujukan}

Alsa, Asmadi. 2014. Pendekatan Kualitatif dan Kuantitatif Serta Kombinasinya dalam Penelitian Psikologi. Yogyakarta: Pustaka Pelajar.

Arikunto, Suharsimi. 2006. Prosedur Penelitian. Jakarta : Rineka Cipta.

Asrohah, Hanun. Dan Alamsyah, Anas Amin . 2015. Pengembangan Kurikulum. Surabaya: Kopertais IV Press.

Depag RI. 2012. Alqur'an dan Terjemahnya. Jakarta : Cahaya Alqur'an.

Fathurrohman, Pupuh. Dan Sutikno, Sobri. 2007. Strategi Belajar Mengajar. Bandung: Refika Aditama.

Andragogi: Volume 2 Nomor 2, 2020 
I wati, Ella yul. 2013. Taman Bacaan Masyarakat Rintisan. Jakarta: Kementrian Pendidikan Dan Kebudayaan Direktorat Jendral Pendidikan Usia Dini, Nonformal Dan Informal.

Kalida, Muhsin. 2012. Fundraising Taman Bacaan Masyarakat (TBM). Yogyakarta: Aswaja.

Kasiram, Moh. 2010. Metodelogi Penelitian Kualitatif- Kuantitatif. Malang: UIN Maliki Press.

Margono. S. 2010. Metodologi Penelitian Pendidikan. Jakarta. Rineka Cipta.

Moleong, Lexy, J. 2005. Metodologi Penelitian Kualitatif. Bandung : Remaja Rosda Karya.

Musfiqon, M. 2012. Metodologi Penelitian Pendidikan. Jakarta: Prestasi Pustakaraya.

Muzzaki, Akh. Dan Kholilah. 2015. Ilmu Pendidikan Islam. Surabaya: Kopertais IV Press.

Nurul Anam dan Moh. Rofid Fikroni, 2020. Rabbani Education: Basic Concepts, Design and Implications of Rabbani Education Learning. Jurnal Tribakti: Jurnal Pemikiran Keislaman, Vol. $31 \quad$ No. 1 Januari. DOI: https://doi.org/10.33367/tribakti.v31i1.975.

Partanto, Pius A. Dan Al Barari, M. Dahlan. 2001. Kamus Ilmiah Populer. Surabaya: Arkola.

Purwanto. 2011. Evaluasi Hasil Belajar. Yogyakarta: Pustaka Pelajar.

Rahmawati, Ratih dan Blasius Sudarsono. 2012. Perpustakaan untuk Rakyat Dialog Anak dan Bapak. Jakarta: CV Sagung Seto.

Rohman, Muhammad. Dan Amri, Sofyan. 2012. Manajemen Pendidikan. Jakarta: Prestasi Pustaka.

Safi'i, Imam. 2020. Model Kepemimpinan Kyai Dalam Membentuk Santri Mandiri Di Era 4.0, Al-Mada: Jurnal Agama Sosial dan Budaya Vol. 3 No 2.

Sa'dullah, Anwar dan Hidayatullah, MF. 2020. Design of Improving The Quality of Human Resources Based on Islamic Schools... Nazhruna: Jurnal Pendidikan Islam Vol.3, no. 3.

Shuihan, Muwahid. Dan Soim. 2013. Manajemen Pendidikan Islam. Yogyakarta: Teras.

Sufyarma. 2004. Kapita Selekta Manajemen Pendidikan. Bandung: Alfabeta.

Sugiyono. 2011. Metode Penelitian Kualitatif- Kuantitatif Dan R\& D. Bandung: Alfabeta.

Tim Dosen Administrasi Pendidikan universitas Pendidikan Indonesia. 2015. Manajemen Pendidikan. Bandung: Alfabeta.

Andragogi: Volume 2 Nomor 2, 2020 
Nurul Anam, Murtasiyatul Jannah

Wiyono, DF. 2017. Pemikiran Pendidikan Islam: Konseptualisasi Pendidikan Karakter Dalam Perspektif Intelektual Islam Klasik. Nidhomul Haq Vol 2, Nomor 3.

Zusnani, Ida. 2013. Manajemen Pendidikan Berbasis Karakter Bangsa. Yogyakarta: Platinum.

Andragogi: Volume 2 Nomor 2, 2020 